\title{
The effect of random porosity field on supercritical carbonation of cement-based materials
}

\author{
Min $\mathrm{Yu}^{\mathrm{a}}$, Hao Bao ${ }^{\mathrm{a}}$, Yin $\mathrm{Chi}^{\mathrm{a}}$, Janqiao Ye $\mathrm{e}^{\mathrm{a}, \mathrm{b}, *}$ \\ a. Department of Civil Engineering, Wuhan University, Wuhan, China \\ b. Department of Engineering, Lancaster University, Lancaster LA1 4YR, UK
}

\begin{abstract}
In this paper, the supercritical carbonation process of cement-based materials is modelled by introducing a random porosity field to simulate the heterogeneous geometry of the carbonation profile. The suitability of two different random fields of porosity, based on the Probability Density Function (PDF) and the Ellipsoidal Autocorrelation Function (EAF) methods, are investigated, respectively, in simulating the distribution of porosity in cement mortar. After incorporating the above random fields into an established supercritical carbonation model, it is found that with some modifications, the EAF method with consideration of spatial correlation produces better simulation of the irregularities of the carbonation zones that have been observed from experimental results. It is also found that for given average porosity and coefficient of variation, the predicted average and maximum carbonation depths have much smaller coefficients of variation. The validated EAF supercritical carbonation model is then used in parametric studies that are conducted to assess the effect of various factors on the carbonation depth of the chemical process.
\end{abstract}

Keywords: Supercritical carbonation, Cement-based materials, random field, Ellipsoidal autocorrelation function, Carbonation depth.

\section{Introduction}

Carbonation is one of the main reasons affecting durability of concrete structures. Ashraf ${ }^{[1]}$ and Šavija et al ${ }^{[2]}$ presented a comprehensive review on the carbonation of cement-based materials, which showed that carbonation could have both positive and negative effects on concrete properties. Carbonation has long been recognized as one of the factors causing reinforcement corrosion $^{[3]}$. Carbonation causes numerous chemo-mechanical changes in the cement mortar, including changes in porosity, pore size distribution and chemistry, that can enhance its strength and reduce its permeability ${ }^{[4-6]}$. The above researches on carbonation of cement based materials were mainly on natural carbonation and its potential negative impact on the performance of existing structures. In the recent years, however, the researchers in this area have paid more attention on studying the beneficial aspects of material carbonation, due to the rapid development of the accelerated and supercritical carbonation techniques. These researches include modification of composition and microstructure of cement based materials using carbonation ${ }^{[7-9]}$, use of $\mathrm{CO}_{2}$ *Correspondence author: Jianqiao Ye [j.ye2@1ancaster.ac.uk] 
curing to improve material properties ${ }^{[10,11]}, \mathrm{CO}_{2}$ capture and storage ${ }^{[12]}$ and carbonation of hazardous water materials ${ }^{[13]}$. Clearly, further research on the carbonation process of cement and concrete is required in order to maximize the benefits and reduce the negative effects caused by carbonation.

Carbonation of cement based materials is a complex multi-physics process ${ }^{[12,14-17]}$, involving chemical reactions of $\mathrm{CO}_{2}$ with $\mathrm{CH}$ and $\mathrm{C}-\mathrm{S}-\mathrm{H}$; gas-liquid two phase flow; dispersion and diffusion of $\mathrm{CO}_{2}$ in water; and temperature propagation. It is also a chemical-physical process of, e.g., calcium leaching and calcite precipitation. It is well known that carbonation will cause material property changes in porosity, coefficients of diffusion and permeability, saturation and $\mathrm{PH}$ value, etc. At the same time, the above changes of material properties will affect the on-going chemical-physical carbonation process. Additionally, the state of $\mathrm{CO}_{2}$ will have an impact on the chemical process. When the temperature and pressure exceed $304.12 \mathrm{~K}$ and $7.38 \mathrm{MPa}$, which are their respective critical values, $\mathrm{CO}_{2}$ is in a supercritical fluid state that has a similar density of fluid and can effuse through porous materials, such as cement based materials, like a gas ${ }^{[18]}$. When the state of $\mathrm{CO}_{2}$ are between supercritical and the natural atmospheric states, the carbonation of cement-based materials is defined as accelerated carbonation. Kinetic models of carbonation subjected to various carbonation conditions have already be developed and used often to predict depth of carbonation in cement-based materials.

Carbonation depth is one of the most important characteristics that are used to define the extent of the chemical process taking place during carbonation. Experimental research has shown that under either natural ${ }^{[19]}$ or supercritical ${ }^{[19]}$ conditions, the boundaries of carbonation zones exhibit irregular shapes characterized by distinctive maximum and minimum carbonation depths. However, current theoretical and numerical models are almost exclusively based on the assumption that the materials are isotropic and homogenous ${ }^{[20]}$, resulting in an average carbonation depth ${ }^{[20]}$. In practical applications, it is the maximum, rather than the average, carbonation depth that is critical in, e,g., reinforcement corrosion analysis. Cement-based materials, especially with added aggregates, are typical examples of nonhomogeneous porous materials that consist of randomly distributed pore in the cement mortar and randomly distributed aggregates. All the above inhomogeneity will have significant impact on the distribution of carbonation depth. Pan, et $\mathrm{al}^{[22]}$ considered the randomness of aggregates in their natural carbonation model and found that though the cement mortar was assumed to be uniform, the existence of aggregates led to a variable carbonation depth. Rimmelé et $\mathrm{al}^{[22]}$ studied random porosity of Portland cement by exposing it to liquid $\mathrm{CO}_{2}$. $\mathrm{Zha}$ and $\mathrm{Yu}^{[15]}$ investigated experimentally the carbonation depth of cement mortar subjected to supercritical conditions, which has shown a carbonation zone of irregular boundaries. Moreover, Lu, et al's ${ }^{[24]}$ experiment confirmed that saturation was also randomly distributed. Clearly, all the above randomness will play a role in the carbonation process of porous materials. Thus, in order to accurately simulate the carbonation process of cement based materials, a model that takes into account material 
inhomogeneity, rather than the current commonly-used model based homogenization, is essential, especially in predicting the maximum carbonation depth.

Currently, material inhomogeneity of concrete is considered by incorporating a randomly distributed aggregates or porosity model. Using a random aggregate model, Han, et al ${ }^{[25]}$ studied the effect of aggregates on carbonation penetration. Huang, et $\mathrm{al}^{[26]}$ and Ruan, et al ${ }^{[27]}$ studied the carbonation process of concrete and obtained a non-uniform distribution of carbonation depth. There have been extensive and well developed research reported in the literature on using random aggregates models in micro-scale concrete modelling for, such as damage and failure ${ }^{[28,29]}$ and ionic transport ${ }^{[30]}$, etc.; For cement mortar, Diamond et al ${ }^{[31]}$ and Shi et $\mathrm{al}^{[32]}$ have shown that a log normal function could be used to model pore size distribution. To the authors' best knowledge, there is no published work on using random porosity models in supercritical carbonation research, though they have been used in some other applications. For example, Liu, et $\mathrm{al}^{[33]}$ used a random porosity field of log normal distribution to simulate the heterogeneous nature of saline aquifers and study the pressure and saturation distributions of the supercritical $\mathrm{CO}_{2}$ after injection; $\mathrm{Li}^{[34]}$ studied the effect of pore size distribution on chloride diffusion in concrete. Both models did not consider spatial correlation of porosity. For detecting void content in composite materials ultrasonically, Lin, et $\mathrm{a}^{[34]}$ developed a two-dimensional porosity model based on the method of ellipsoidal autocorrelation function, where spatial correlation was considered. Since the size of pores in cement mortar is small, it is difficult to simulate its pore distribution by following a random aggregate distribution model. Using a random distribution field to define the magnitude of porosity and spatial inhomogeneity of cement mortar can be a better option.

To address the issues raised above, this paper, on the basis of Liu, et al's ${ }^{[33]}$ probability density function method and Lin, et al's ${ }^{[35]}$ ellipsoidal autocorrelation function method, proposes a random distribution field for cement based materials that can take into account both random distribution of porosity and its spatial correlation. Introducing the improved random field into the supercritical carbonation model developed previously by the authors ${ }^{[15]}$, new studies are carried out on the supercritical carbonation of cement based materials. Comparisons are made against the experimental tests reported also by the authors ${ }^{[15]}$ to investigate the effect of random distribution of porosity in cement mortar on the carbonation depth, such that the irregular carbonation depths, particularly, the maximum and minimum depths can be statistically explained and predicted.

\section{Random field model of porosity for cement-based materials}

Random field models of porosity are studied in this section for modelling supercritical carbonation process in cement-based materials. The random field models of porosity based on the method of probability density function ${ }^{[33]}$ and the method of ellipsoidal autocorrelation function ${ }^{[35]}$ are compared.

\subsection{Random field model of porosity based on probability density function}

*Correspondence author: Jianqiao Ye [j.ye2@lancaster.ac.uk] 
A random porosity field based on probability density function was used to simulate the heterogeneous nature of saline aquifers ${ }^{[33]}$, where the function was assumed to be lognormal distribution, as shown in Eq.(1).

$$
f(x)=\frac{1}{x \sigma \sqrt{2 \pi}} \exp \left[-\frac{(\ln x-\mu)^{2}}{2 \sigma^{2}}\right] \quad 0<x<1
$$

where $x$ is the random porosity taking between 0 and $1 ; f(x)$ is the probability density of $x ; \mu$ and $\sigma$ are the $\log$ mean and log standard deviation.

The relationship between $\mu, \sigma$, the average porosity, $\varepsilon_{m}$, and the variance of porosity $v$ can be represented by Eqs.(2) and (3). The coefficient of variation $C V$ is described in Eq.(4):

$$
\begin{gathered}
\mu=\ln \left(\frac{\varepsilon_{m}^{2}}{\sqrt{v+\varepsilon_{m}^{2}}}\right) \\
\sigma=\sqrt{\ln \left(\frac{v}{\varepsilon_{m}{ }^{2}}+1\right)} \\
C V=\frac{\sqrt{v}}{\varepsilon_{m}}
\end{gathered}
$$

In order to generate a lognormal distribution of porosity defined by Eq.(1), a random generator based on the Monte Carlo method ${ }^{[36]}$, which can generate any required probability density, was used. Fig.1(a) shows the generated porosity distribution with an average porosity of 0.13 and a variance of 0.01 . The probability density function of Fig.1(a) is shown in Fig.1(b) and compared with the one calculated from Eq.(1). The comparisons show that the probability density function of the generated porosity distribution is very close to that of Eq.(1).

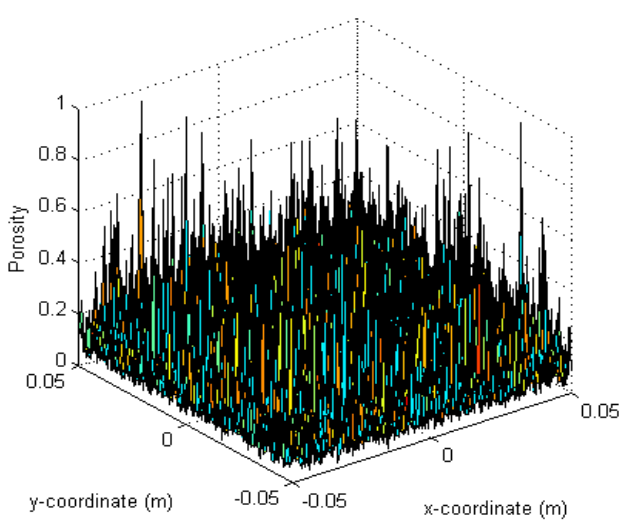

a) Porosity distribution

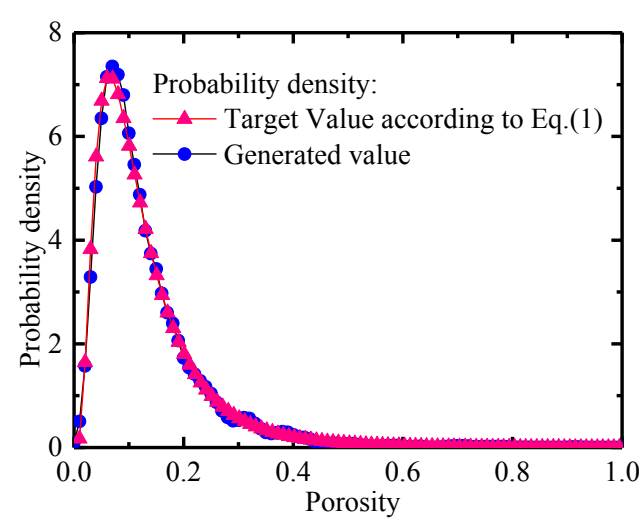

b) Probability density function

Figure 1 Random distribution of porosity based on the method of probability density function

\subsection{Random field model of porosity based on the ellipsoidal autocorrelation function}

A literature review showed that a random field model can also include spatial correlation effect. For example, researchers ${ }^{[35,37,38]}$ have used ellipsoidal autocorrelation function to generate random field to take into account spatial correlation. 
Lin, et $\mathrm{al}^{[35]}$ developed a two-dimensional (2-D) random field model of porosity based on the method of ellipsoidal autocorrelation function for random voids distribution in composite materials. The random distribution is characterized by an ellipsoidal autocorrelation function in the medium. Eq.(5) is the governing equation of random voids distribution based on the method of ellipsoidal autocorrelation function ${ }^{[35]}$.

$$
\phi(x, y)=\exp \left[-\left(\frac{x^{2}}{a^{2}}+\frac{y^{2}}{b^{2}}\right)^{\frac{1}{1+r}}\right]
$$

where $\phi$ is an ellipsoidal autocorrelation function; $a$ and $b$ are the autocorrelation lengths in the $x$ and $\mathrm{y}$ directions, respectively; $r$ is the roughness factor (when $r=0$, it is the Gaussian autocorrelation function).

By following Lin, et al ${ }^{[35]}$,s process, the porosity distribution with the same average porosity and variance as those of Fig.1(a) is shown in Fig.2(a). A close study of the porosity distribution in Fig.2(a) showed that the porosity exhibited approximately a normal distribution, as shown in Fig.2(b). Also, the distribution of porosity is ranged only from 0.08 to 0.16 , which is obviously too restrictive to cover a broader range of porosity distribution. In order to generate a log normal distribution of porosity and cover a full range of porosity distribution, the process proposed by Lin, et $\mathrm{al}^{[35]}$ was modified in this research and the modified procedure is shown in the flow chart in Fig.3, where log mean and log standard deviation are used and the final random field is expressed in terms of an exponential function (see the right branch of the last step in Fig. 3).

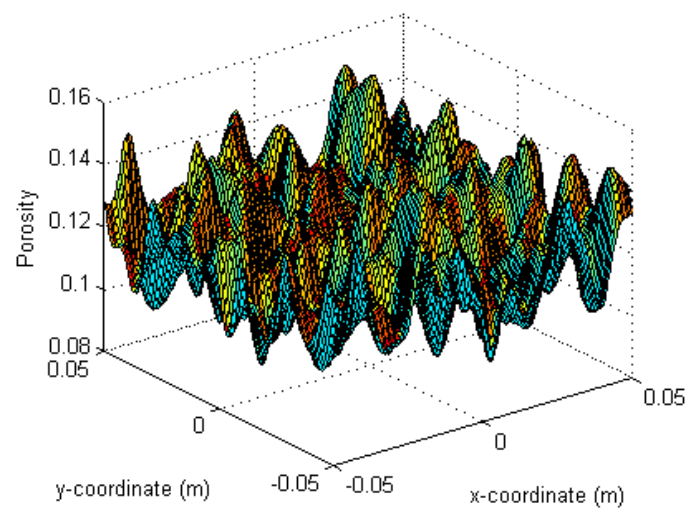

a) Porosity distribution

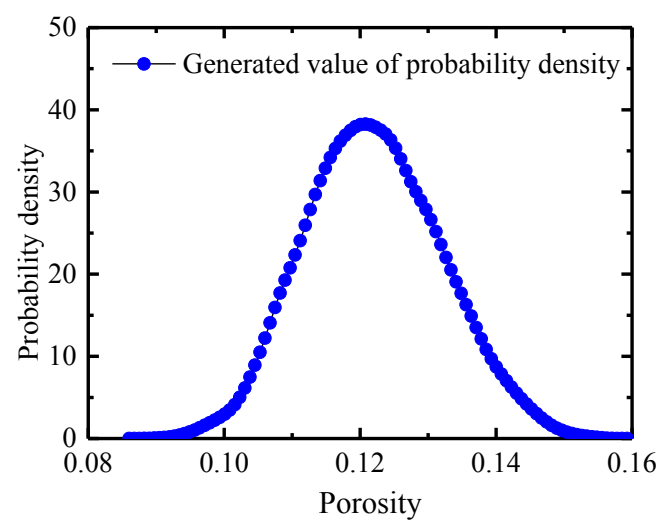

b) Probability density of porosity

Figure 2 Random distribution of porosity based on the method of ellipsoidal autocorrelation function 


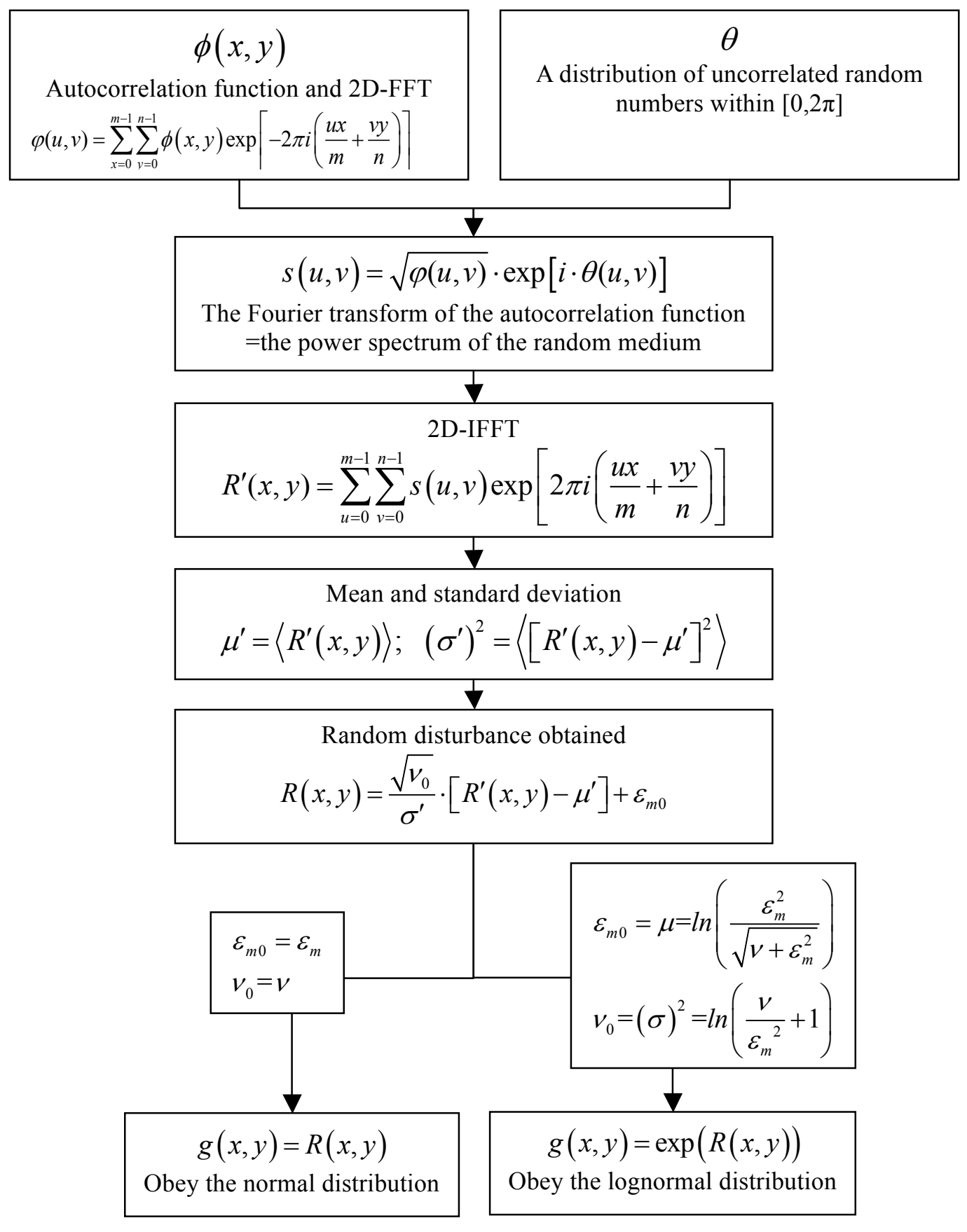

Figure 3 The flow chart of generating the random porosity model based on the method of ellipsoidal autocorrelation function

The distribution of porosity using the modified ellipsoidal autocorrelation function method is presented in Fig.4(a), where the spatial correlation of porosity is evident. The calculated probability density of Fig.4(a) is shown in Fig.4(b) and compared with the target probability of Eq.(1). It is clear that the modified ellipsoidal autocorrelation function method has now provided a $\log$ normal distribution of porosity that is ranged from 0 to 1 . The comparisons also show that the probability density from the modified ellipsoidal autocorrelation function method agrees well with the targeted log normal distribution. 


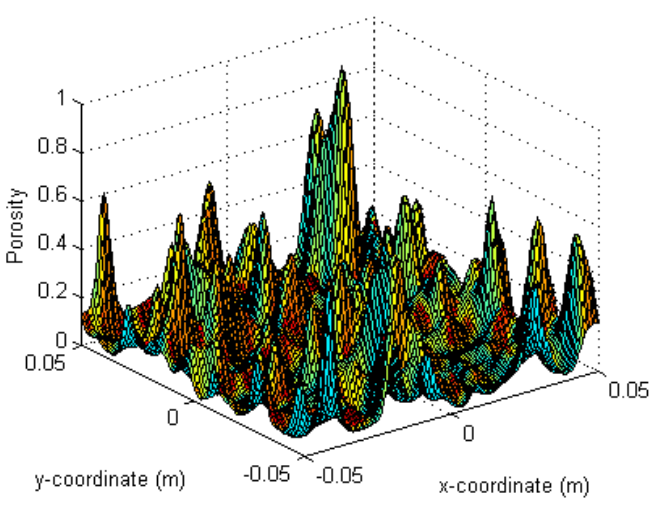

a) Distribution of porosity

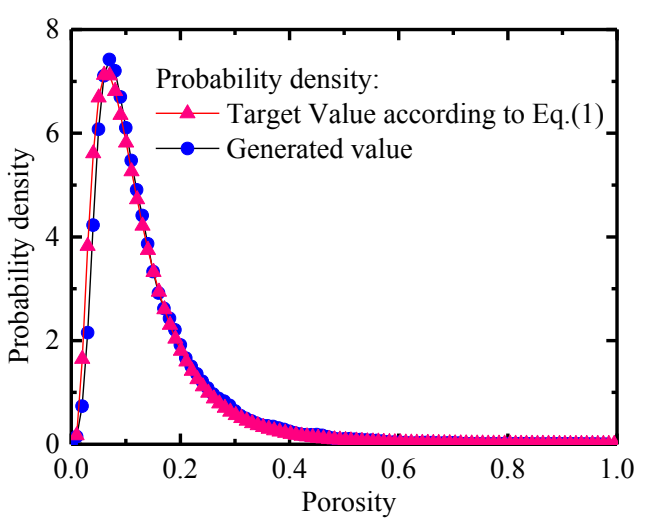

b) Validation of porosity model

Figure 4 Random distribution of porosity based on the method of modified ellipsoidal autocorrelation function

From the above analysis, it can be seen that both the random generator based on the Monte Carlo method and the modified ellipsoidal autocorrelation function method can produce almost equally well the required log normal distribution of porosity. The suitability of the methods in simulating the distribution of pores in a supercritical carbonation process will be further tested in the next section.

\section{Theoretical model for supercritical carbonation of cement-based materials}

Concrete carbonation is a complex multi-physics coupling process that can be described by the rate of equation of chemical reactions, mass conservation equation, momentum conservation equation and energy conservation equation. The mathematical model of supercritical carbonation is briefly described below and the details of the model can be found from $\mathrm{Zha}$ and $\mathrm{Yu}^{[15]}$.

\subsection{Governing equations of supercritical carbonation}

Eqs. (6), (7), (8), and (9) below are the governing equations of supercritical carbonation, in which the rate of chemical reaction, mass conservation for gas-liquid two phase flow, diffusion and dispersion of $\mathrm{CO}_{2}$ in water, energy conservation for porous medium, and the solubility of $\mathrm{CO}_{2}$ in water are all considered.

$$
\begin{gathered}
\frac{\partial R_{c}}{\partial t}=\alpha_{1} \times f_{1}(h) \times f_{2}\left(g_{v}\right) \times f_{3}\left(R_{c}\right) \times f_{4}(T) \\
\frac{\partial(g)}{\partial t}=\frac{\partial\left(m_{c o_{2}}\right)}{\partial t} \\
\frac{\partial\left(n S_{\alpha} \rho_{\alpha}\right)}{\partial t}+\nabla \cdot\left(\rho_{\alpha} u_{\alpha}\right)=q_{\alpha} \\
r \quad k_{\alpha}=-\frac{k k_{r \alpha}}{\mu_{\alpha}}\left(\nabla P_{\alpha}-\rho_{\alpha}^{g} g\right)
\end{gathered}
$$




$$
\left(\rho C_{q}\right)_{e f f} \frac{\partial T}{\partial t}=\nabla \cdot\left(k_{e f f} \nabla T\right)-\left(C_{g} \rho_{g} \stackrel{u}{g}_{g}+C_{w} \rho_{w} \stackrel{r}{u_{w}}\right) \nabla T
$$

where $R_{c}$ is the degree of carbonation; $g$ is the mass concentration of $\mathrm{CO}_{2}$ in water; $P_{\alpha}$ is the pressure of phase $\alpha$; subscript $\alpha$ refers to $w$ for liquid phase and $g$ for gaseous phase; $T$ denotes temperature. The detailed description of the other parameters can be found in $\mathrm{Zha}$ and $\mathrm{Yu}^{[15]}$.

In Eq.((8a)b), $k$ is the intrinsic permeability according to Bary ${ }^{[39]}$ and Shen ${ }^{[12]}$ :

$$
k=k_{0}\left(\frac{n}{n_{0}}\right)^{3} \cdot\left(\frac{1-n_{0}}{1-n}\right)^{2}
$$

where, $k_{0}$ is the initial intrinsic permeability before carbonation; $n$ is the porosity of material that decreases during carbonation. $n_{0}$ is the initial porosity that depends mainly on the average porosity $\varepsilon_{m}$, and the coefficient of variation $C V$, which are derived from a random field model of porosity, e.g., a model from Section 2.

\subsection{Initial and boundary conditions}

The governing equations presented in the above section can be solved by imposing appropriate initial and boundary conditions. In this study, the conditions used in ${ }^{[15]}$ are introduced. They are

$$
\begin{gathered}
R_{c}=R_{c 0}=0, P_{g}=P_{g 0}, P_{w}=P_{w 0}, g=g_{0}=0, T=T_{0}, t=0 \text { on } \Omega \\
n \cdot \nabla R_{c}=0, n \cdot \nabla g=0 \text { on } \Gamma_{2} \\
P_{g}=P_{g, s u r}, P_{w}=P_{w, s u r}, T=T_{\text {sur }} \text { on } \Gamma_{1}
\end{gathered}
$$

where $R_{c 0}(=0)$ is the initial conditions specifying the degree of carbonation; $P_{g 0}$ is the initial gas pressure; $P_{w 0}$ is the initial water pressure that can be determined by initial gas pressure $P_{g 0} ; g_{0}$ is the initial concentration of dissolved $\mathrm{CO}_{2}$ in water, setting to be zero; $T_{0}$ is the initial temperature; $n$ is the normal vector of the boundary; $\Gamma_{2}$ is the boundary using Neumann's conditions; $\Gamma_{1}$ is the boundary using Dirichlet's conditions; $P_{g, s u r}$ is the surrounding gas pressure that is a function of time, $P_{w, s u r}$ is the surrounding liquid pressure, and $T_{\text {sur }}$ is the surrounding temperature. The detailed description of the other parameters can be found in $\mathrm{Zha}$ and $\mathrm{Yu}^{[15]}$.

\section{Effects of random field modeling on the supercritical carbonation process in cement mortar}

Fig. 5 Shows the carbonation profile of the cement mortar and concrete blocks experimentally tested in the previous work ${ }^{[15]}$. The size of the cement mortar and concrete cubes are both $100 \times 100 \times 100(\mathrm{~mm})$. The cement mortar and concrete blocks were all subjected to supercritical condition for 5.8 hours. Fig. 5 shows clearly that the non-carbonized zones around the centre of the blocks have irregular boundaries and the maximum and minimum carbonation depths (perpendicular distance to a side of the section) are significantly different. 


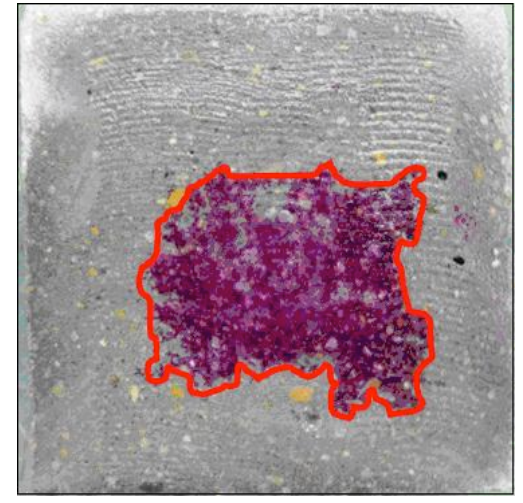

a) Cement mortar block

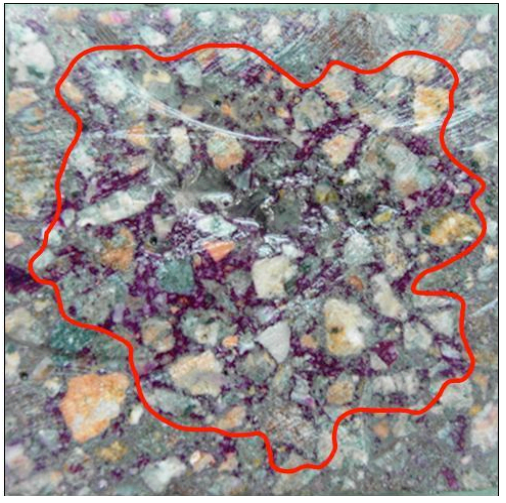

b) Concrete block

Figure 5 Carbonation depth of cement mortar and concrete test blocks ${ }^{[15]}$

To simulate the carbonation process shown in Fig.5, two-dimensional cement mortar and concrete models were developed, in which the two random fields of porosity distribution discussed in Section 2 were implemented, respectively, to simulate the random nature of the materials. The size of the $2 \mathrm{D}$ models of the cement mortar and concrete cubes are both $100 \times 100$ $(\mathrm{mm})$. It is assumed that the cubes have the following typical porosity properties as listed in Table 1.

Table 1 Parameters for cement mortar and concrete

\begin{tabular}{llll}
\hline Materials & Porous properties & Value & References \\
\hline \multirow{3}{*}{ Cement mortar } & Average porosity, $\varepsilon_{m}$ & 0.13 & {$[40]$} \\
& Coefficient of variation, $C V$ & 0.77 & \\
& Intrinsic permeability, $k_{0}$ & $35 \times 10^{-21} \mathrm{~m}^{2}$ & {$[40]$} \\
\hline \multirow{3}{*}{ Concrete } & Average porosity, $\varepsilon_{m}$ & 0.122 & {$[41]$} \\
& Coefficient of variation, $C V$ & 0.50 & \\
& Intrinsic permeability, $k_{0}$ & $3 \times 10^{-21} \mathrm{~m}^{2}$ & {$[41]$} \\
\hline
\end{tabular}

\subsection{The effects of randomness and spatial correlation on carbonation of cement mortar}

$\mathrm{COMSOL}^{[42]}$ was used as a numerical platform to simulate the chemical reactions associated with carbonation and the results were compared with available laboratory test results ${ }^{[15]}$. Details of how the supercritical carbonation equations were solved by COMSOL can been found in Zha and $\mathrm{Yu}^{[15]}$. In this paper, the initial porosity of the supercritical carbonation model was derived first from the random field model in Section 2, using the given average porosity and coefficient of variation. The initial porosities at each node were then saved in Matlab as a mat file to be allocated to node the supercritical carbonation COMSOL model. Finally a subroutine was written to introduce the saved file to the COMSOL model to implement the random distribution of porosity in the cement.

For the sake of comparisons, the predicted carbonation for with and without considering randomness and spatial correlation of the porosity of the cement mortar blocks are shown in 
Figure 6. Fig. 6(a-c) show, respectively, the sections with a uniformly distributed porosity, a randomly distributed porosity without spatial correlation (PSD) and a randomly distributed porosity with spatial correlation (EAF). To include spatial correlation in Fig. 6 (c), it was assumed that the autocorrelation lengths, $a$ and $b$, in equation (5) were both 0.005 . Fig.6(d-f) show the respective carbonation results of the cement mortar blocks.

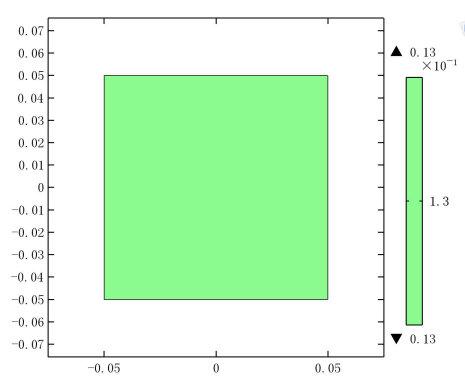

a) Uniform porosity distribution

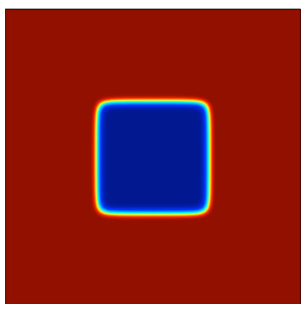

d) Carbonation of model (a)

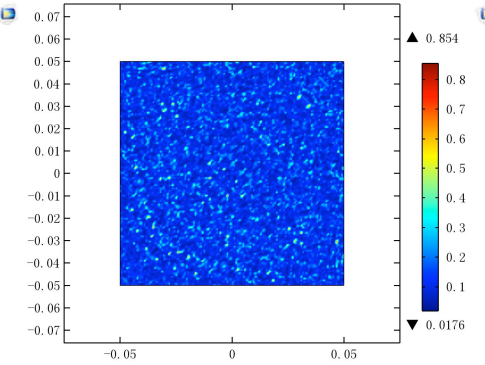

b) Random porosity distribution without spatial correlation

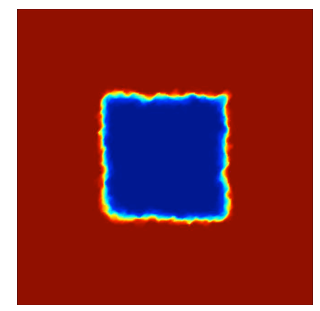

e) Carbonation of model (b)

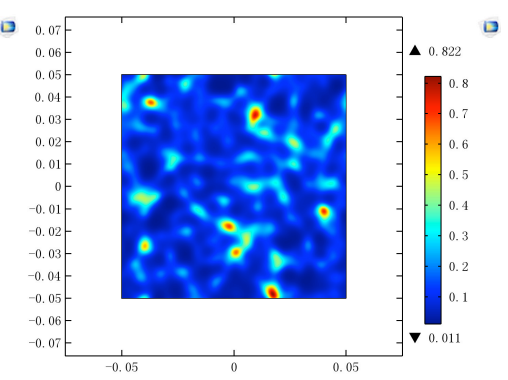

c) Random porosity distribution with spatial correlation

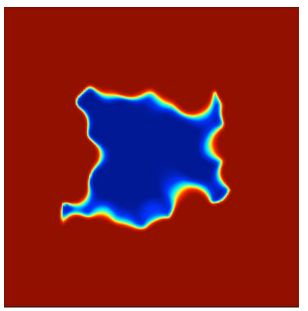

f) Carbonation of model (c)

Figure 6 Porosity model and carbonation results of cement mortar blocks

From the above results and comparisons with the test results shown in Fig.6, it can be seen that the porosity distribution models of Fig.6(a) and Fig.6(b) cannot satisfactorily capture the irregular boundaries of the non-carbonated zones, while the modified ellipsoidal autocorrelation function model, which takes into account spatial correlation, is capable of providing more realistic and a better prediction to the carbonation depths. Therefore, in the following sections, the modified ellipsoidal autocorrelation function method will be incorporated into the supercritical carbonation model mentioned in Section 3 to study the carbonation process of cement mortar.

\subsection{Effect of random sampling on the variation of carbonation depths in cement mortar}

Applying the above carbonation model for cement mortar blocks with the porosity properties shown in Table 1 ( $\varepsilon_{m}=0.13$ and a $C V=0.77$ ), the carbonation process of 12 random samples were studied after they were in the same supercritical condition for 5.8 hours. For illustration purpose, only the cross-sections of 6 samples are shown here in Figure 7, where the central blue areas represent the non-carbonized zones. In Figure 7, the maximum and minimum carbonation depths are also shown, respectively. 


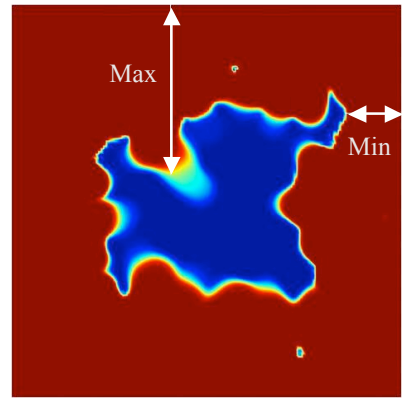

a) Sample 1

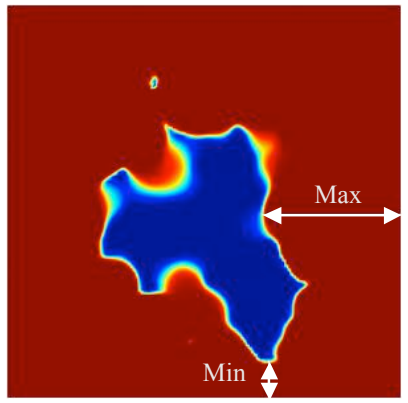

d) Sample 4

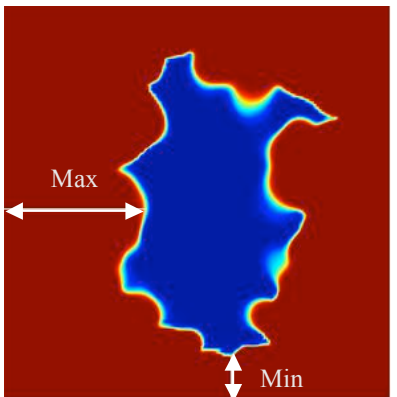

b) Sample 2

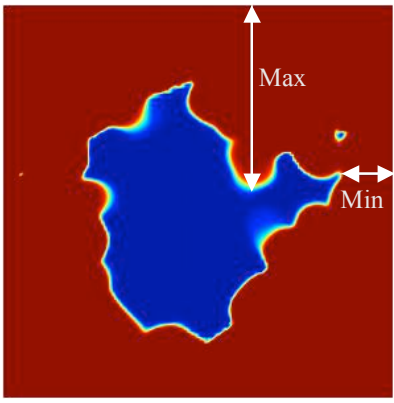

e) Sample 5

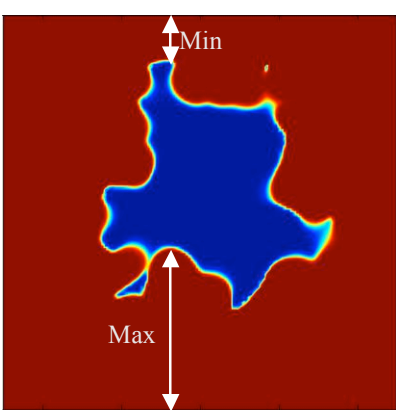

c) Sample 3

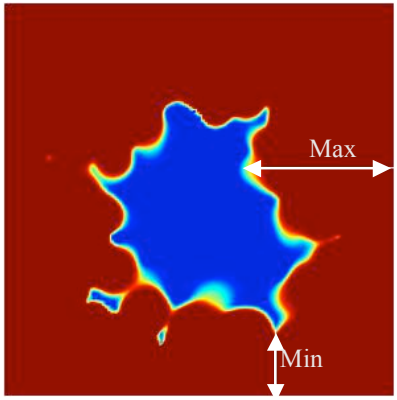

f) Sample 6

Figure 7 Carbonation results of 6 cement mortar samples

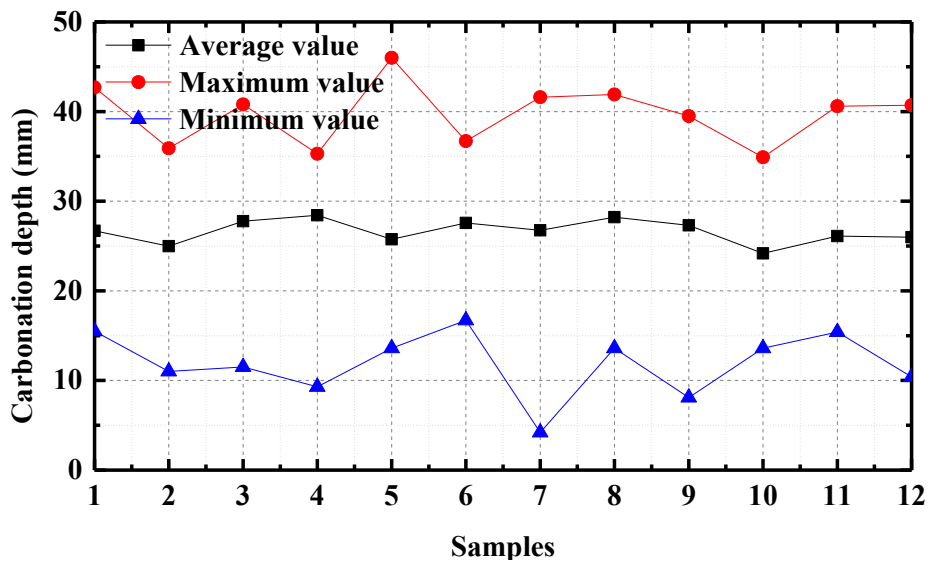

Figure 8 Carbonation depths of 12 cement mortar samples

Fig. 8 shows the average, maximum and minimum carbonation depths of the 12 cement mortar samples with the same average porosity and coefficient of variation. It can be seen that the results are relatively consistent. As expected, the maximum and the minimum depths fluctuate more than the average depth.

Table 2 presents detailed comparisons between the test ${ }^{[15]}$ and the simulation results from the 12 samples illustrated in Fig.8. In Table 2, the simulated average carbonation depths, the maximum and the minimum carbonation depths of the 12 sample obtained from the modified ellipsoidal autocorrelation function model are presented along the carbonation depths obtained from the uniform porosity model.

Table 2 The average, maximum and minimum carbonation depth of cement mortar 


\begin{tabular}{lccc|c}
\hline \multirow{2}{*}{ Variables } & \multirow{2}{*}{ Test $^{[15]}$} & \multirow{2}{*}{$\begin{array}{c}\text { Uniform } \\
\text { model }\end{array}$} & & \multicolumn{2}{c}{ Modified EAF model } \\
\cline { 5 - 6 } & & & Average & CV \\
\hline Average carbonation depth, $D(\mathrm{~mm})$ & 26.4 & 29.5 & 26.6 & 0.05 \\
Maximum carbonation depth, $D_{\max }(\mathrm{mm})$ & 35.7 & 29.5 & 39.7 & 0.09 \\
Minimum carbonation depth, $D_{\min }(\mathrm{mm})$ & 17.9 & 29.5 & 11.9 & 0.30 \\
\hline
\end{tabular}

From Table 2, it can be seen that the modified ellipsoidal autocorrelation function model can provide much better predictions to the carbonation depths than those from the uniform porosity model. Especially, the modified ellipsoidal autocorrelation function model provides a good estimate of not only the average carbonation depth, but also the maximum and the minimum carbonation depths. Moreover, from the samples with a given coefficient of variation of porosity (0.77), the coefficients of variation of the average, the maximum and the minimum carbonation depths are far smaller and are, respectively, 0.05, 0.09 and 0.30. Especially, the smallest coefficient of variation of the average carbonation depth suggests that the average carbonation depth is least sensitive to the variation of porosity, followed by those of the maximum and the minimum depths.

Overall, it can be concluded that the proposed random porosity model that considers spatial correlation can provide a much improved prediction to the overall cement mortar carbonation process.

\subsection{The influence of average porosity and coefficient of variation on carbonation process of} cement mortar

In the previous sections, an improved cement mortar carbonation model was developed based on the consideration of spatially correlated random porosity, and validated against available test results. In this section, the model is applied to predict the carbonation depths for cement mortar blocks having various average porosities and coefficients of variation. The blocks have the same dimensions and under the same supercritical carbonation condition as those analyzed in the previous section. The range of the average porosities considered here is from 0.09 to 0.21 , representing typical cement mortar used in construction design ${ }^{[43]}$. The coefficients of variation are chosen as $0,0.4,0.5,0.6,0.7,0.8$. Fig. 9. shows the carbonation results of the mortar blocks based on the modified ellipsoidal autocorrelation function porosity model. When the coefficient of variation, $\mathrm{CV}$, is 0 , the porosity is distributed uniformly, resulting in a constant carbonation depth and a regular non-carbonated zone. Irregularities occur when the CV becomes non-zero. Figure 9 shows the images of the predicted carbonation. 


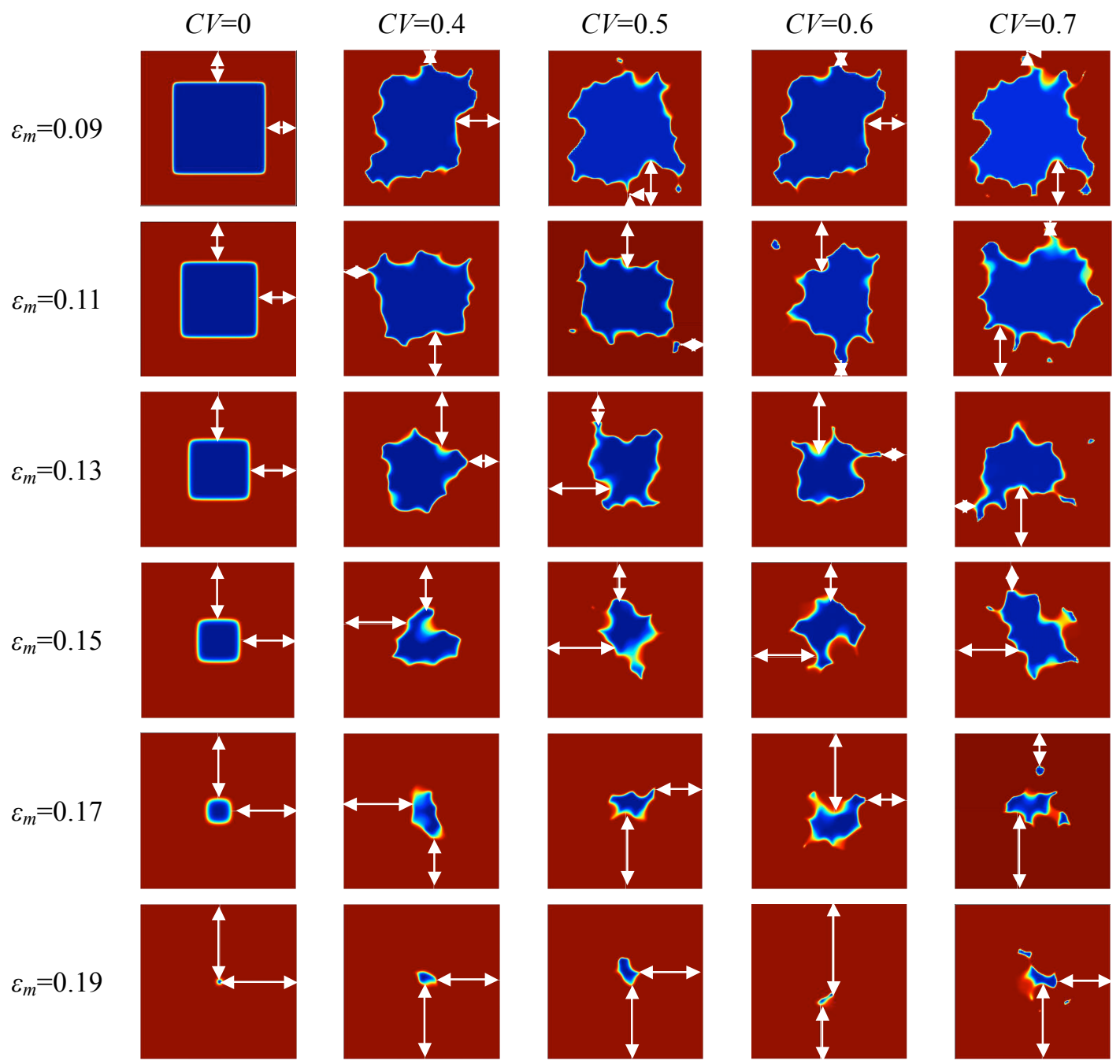

Figure 9 Carbonation of mortar blocks based on the random porosity model

Fig.10 shows the measured minimum, average and maximum carbonation depths from Fig.9 for the selected range of average porosities and coefficients of variation.

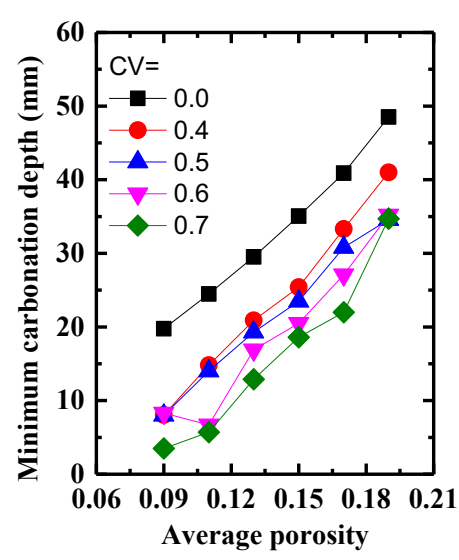

a) Minimum depth

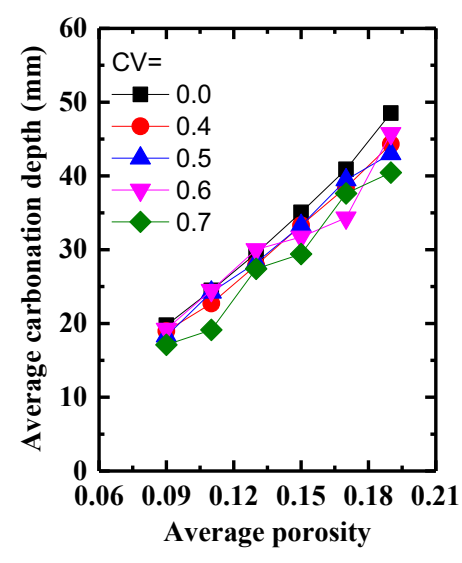

b) average depth

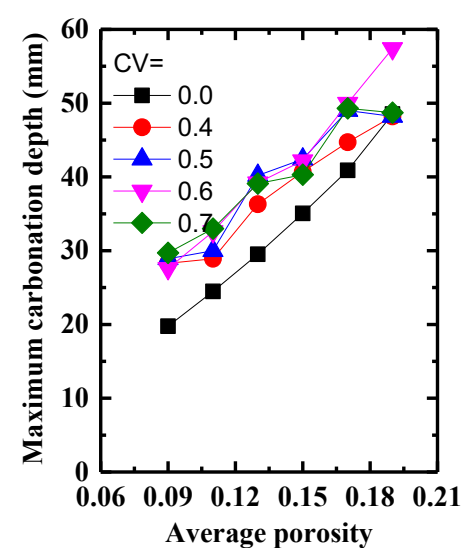

c) Maximum depth

Figure 10. Effect of average porosity and coefficient of variation on carbonation depth 
As expected, for a constant coefficient of variation, the carbonation depth always increases with the increase of average porosity. For a constant average porosity, the carbonation depths do not show any definitive relationship with the coefficient of variation. However, the coefficient of variation has the least impact on the average carbonation depth, while has the highest impact on the minimum carbonation depth. This observation coincides with the conclusion drawn from Table 2. Also it is a general trend that an increase of coefficient of variation will normally lead to a decrease (increase) of the maximum (minimum) carbonation depths.

\section{Effects of random porosity field on the supercritical carbonation process in concrete}

\subsection{The effects of randomness and spatial correlation on carbonation of concrete}

In this section, the random porosity field used in the previous section for cement mortar is applied to simulate carbonation of concrete where randomly distributed aggregates present. It is assumed that aggregates are impermeable ${ }^{[30]}$ due to their much lower porosity. Fig.11(a-c) show the randomly distributed aggregates within cement mortar blocks having uniformly distributed porosity, randomly distributed porosity without spatial correlation and randomly distributed porosity with spatial correlation, respectively. The distribution of the aggregates shown in Fig.11 is an approximate mapping of a laboratory test block used for validating the numerical model. Similar to the comparisons made in Fig.6 for cement mortar, Fig.11(d-f) show the respective carbonation profile of the blocks using the three different porosity fields.

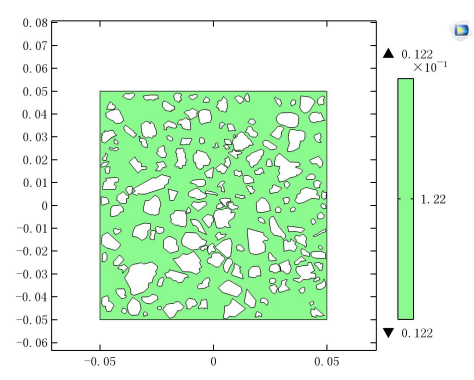

a) Uniform field

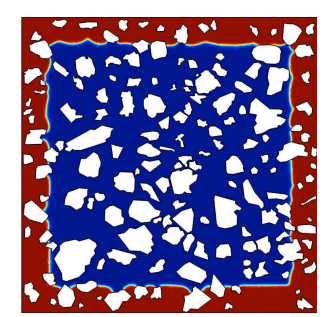

d) Carbonation of model (a)

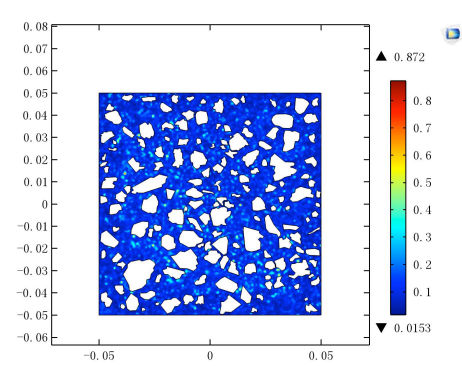

b) Random field without spatial correlation

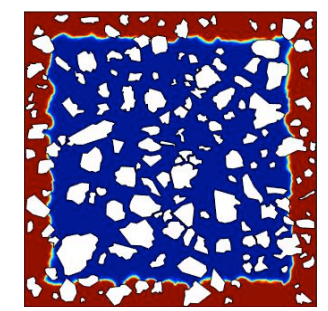

e) Carbonation of model (b)

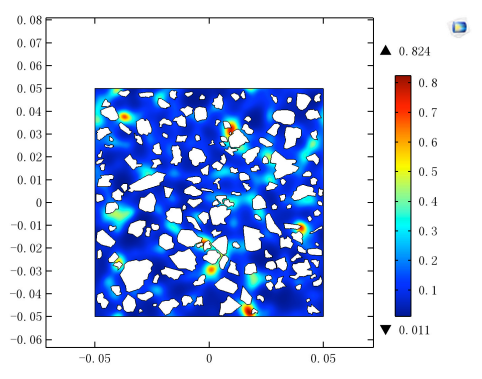

c) Random field with spatial correlation

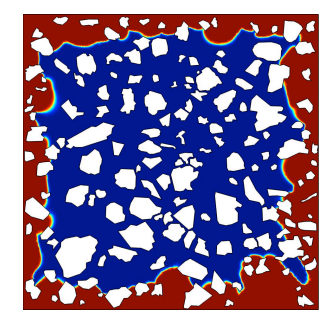

f) Carbonation of model (c)

Figure 11 Porosity models and carbonation results of concrete blocks

From Fig.11(f) and a comparison with the test results shown in Fig.5(b) for the concrete 
blocks, once again, the modified ellipsoidal autocorrelation function model with spatial correlation provides the best simulation of the irregularities of the non-carbonated zone (in blue), which shows significant difference between the maximum and minimum carbonation depths.

\subsection{Effect of random sampling on the variation of carbonation depths in concrete}

Applying the above carbonation model for concrete blocks, the carbonation profiles of six concrete samples after being in supercritical condition for $5.8 \mathrm{~h}$ were studied. Two cases, based on the selection of the average porosity $\varepsilon_{m}$, coefficient of variation $C V$ and intrinsic permeability $k_{0}$, are presented, respectively in Fig.12 and Fig.13. Fig.12 presents the carbonation profile of the section of the concrete blocks when the cement mortar takes the overall concrete porosity shown in Table $1\left(\varepsilon_{m}=0.122, C V=0.5\right.$ and $\left.k_{0}=3 \times 10^{-21} \mathrm{~m}^{2}\right)$. Fig. 13 , however, used the cement properties $\left(\varepsilon_{m}=0.13, C V=0.5\right.$ and $\left.k_{0}=1.5 \times 10^{-20} \mathrm{~m}^{2[40]}\right)$ for the cement mortar in the concrete blocks.

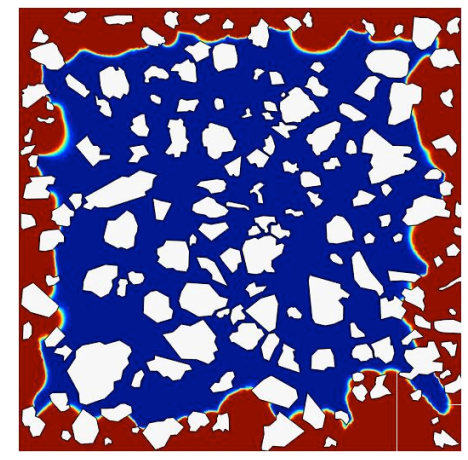

a) Sample 1

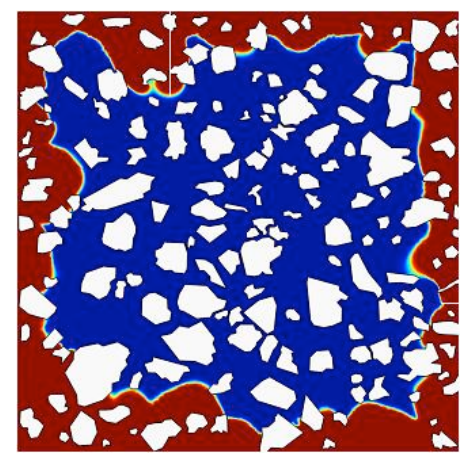

d) Sample 4

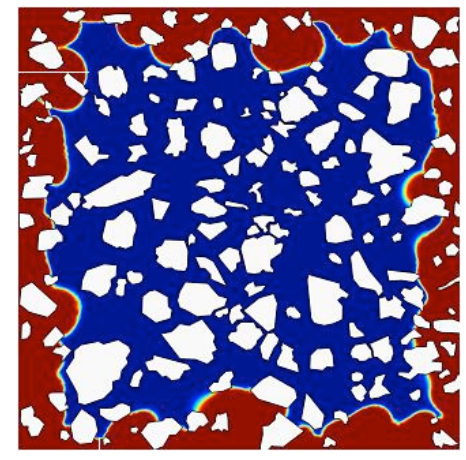

b) Sample 2

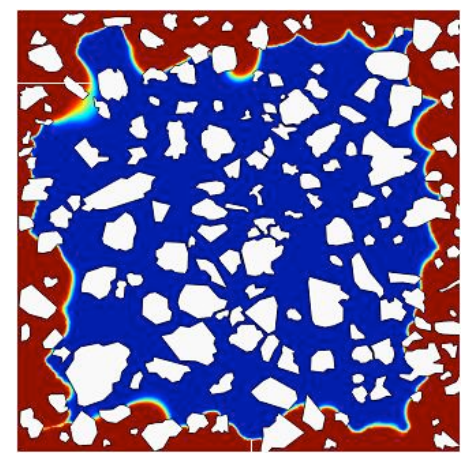

e) Sample 5

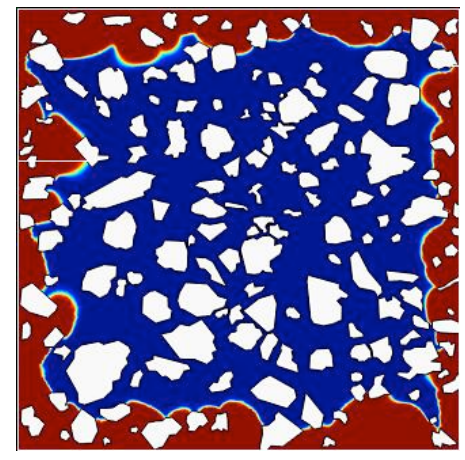

c) Sample 3

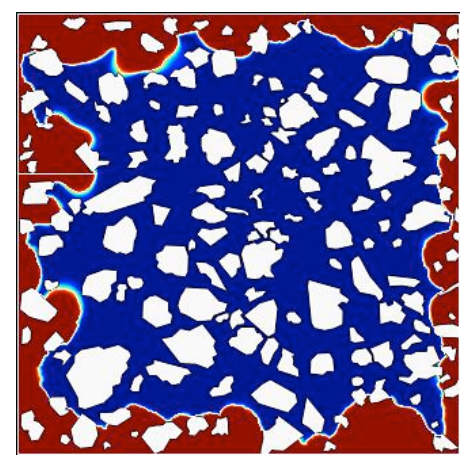

f) Sample 6

Figure 12 Carbonation of 6 concrete samples $\left(\varepsilon_{m}=0.122, C V=0.5\right.$ and $\left.k_{0}=3 \times 10^{-21} \mathrm{~m}^{2}\right)$ 


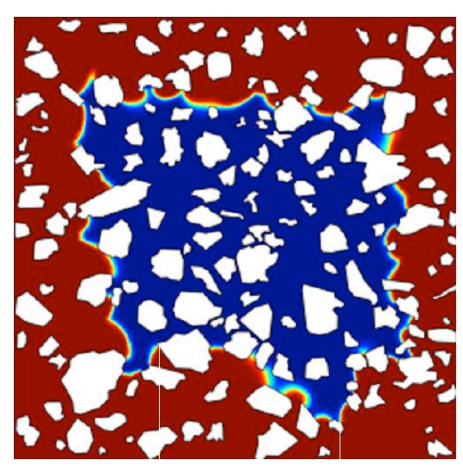

a) Sample 1

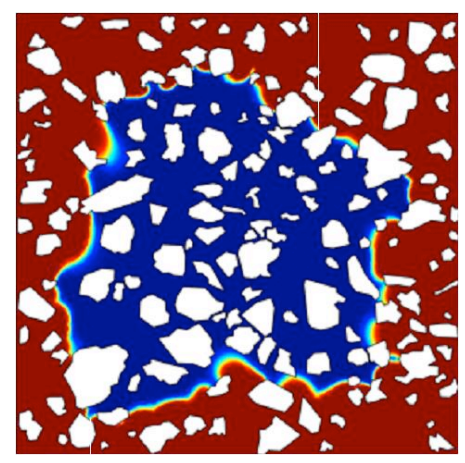

d) Sample 4

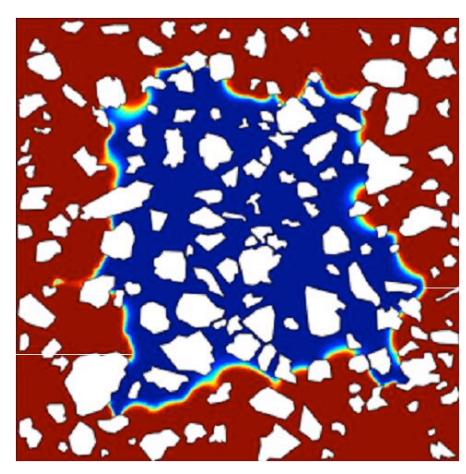

b) Sample 2

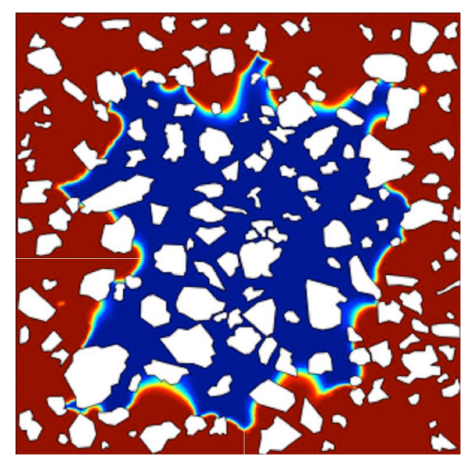

e) Sample 5

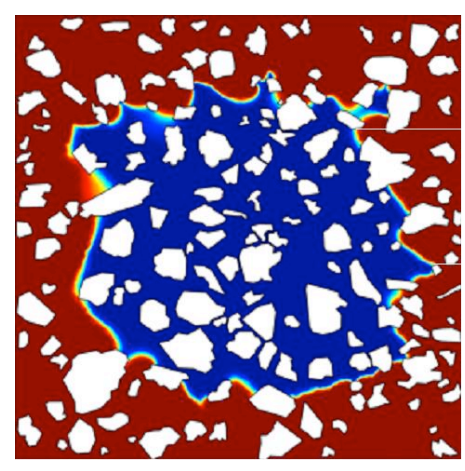

c) Sample 3

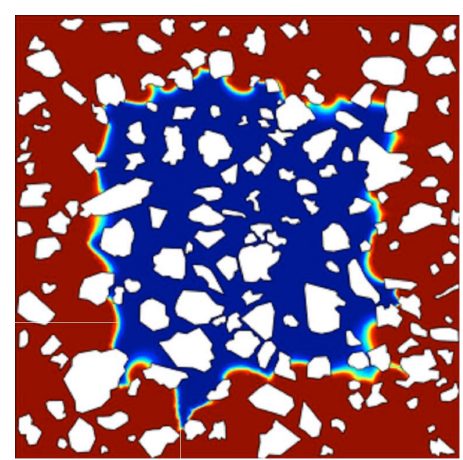

f) Sample 6

Figure 13 Carbonation of 6 concrete samples $\left(\varepsilon_{m}=0.13, C V=0.5\right.$ and $\left.k_{0}=1.5 \times 10^{-20} \mathrm{~m}^{2}\right)$

Fig.14(a) and Fig.14(b) show the respective average, maximum and minimum carbonation depths of the 6 concrete samples observed from Fig.12 and Fig.13. It can be seen that for both cases, the results are relatively consistent across the six samples.

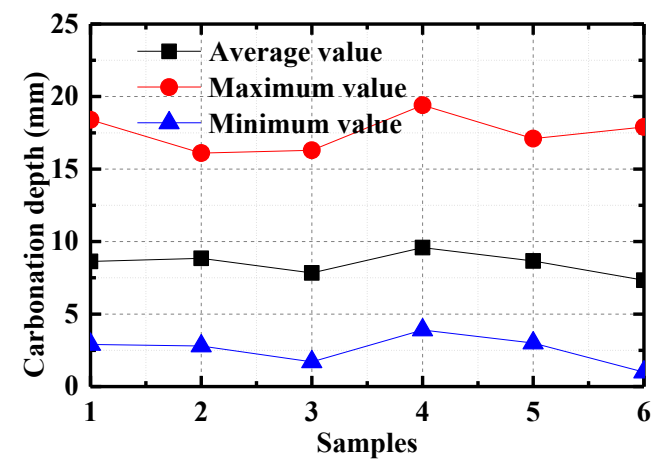

a) Using concrete parameters

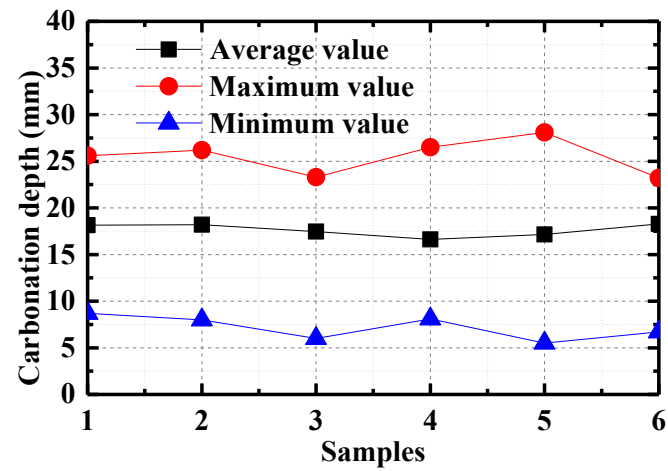

b) Using cement mortar parameters

Figure 14 Carbonation depths of 6 concrete samples

Table 3 presents detailed comparisons between the laboratory tests and the simulated average maximum and minimum carbonation depths taken as the respective average of the six samples.

Table 3 The average, maximum and minimum carbonation depth of concrete

\begin{tabular}{cccc|cc}
\hline \multirow{2}{*}{$\begin{array}{c}\text { Carbonation depth } \\
\text { /mm }\end{array}$} & Test $^{[15]}$ & \multicolumn{2}{c|}{$\varepsilon_{m}=0.122, k_{0}=3 \times 10^{-21} \mathrm{~m}^{2}$} & \multicolumn{2}{c}{$\varepsilon_{m}=0.13, k_{0}=15 \times 10^{-21} \mathrm{~m}^{2}$} \\
\cline { 2 - 6 } & & $\begin{array}{c}\text { Uniform } \\
\text { model }\end{array}$ & $\begin{array}{c}\text { Modified EAF } \\
\text { model }\end{array}$ & $\begin{array}{c}\text { Uniform } \\
\text { model }\end{array}$ & $\begin{array}{c}\text { Modified EAF } \\
\text { model }\end{array}$ \\
\hline
\end{tabular}

*Correspondence author: Jianqiao Ye [j.ye2@lancaster.ac.uk] 


\begin{tabular}{lccc|c|c|c|c}
\hline & & & Average & CV & & Average & CV \\
\hline Average, $D$ & 12.5 & 8.6 & 8.5 & 0.09 & 18.5 & 17.6 & 0.04 \\
Maximum, $D_{\max }$ & 27.0 & 9.7 & 17.5 & 0.07 & 20.3 & 25.5 & 0.08 \\
Minimum, $D_{\min }$ & 2.7 & 6.3 & 2.6 & 0.41 & 15.3 & 7.2 & 0.18 \\
\hline
\end{tabular}

From Table 3, it can be observed that in general the modified ellipsoidal autocorrelation function provides much better predictions to the maximum and minimum carbonation depths of the concrete block than those obtained from using the uniform porosity model. As observed from Table 2 for cement mortar, using the modified ellipsoidal autocorrelation function method, the coefficients of variation of the average and the maximum carbonation depths of the predicted results are much smaller than the coefficient of variation of porosity (0.5). However, from the comparisons with the test results shown in Table 3, the simulated carbonation depths are less satisfactory for the concrete than for the cement mortar (Table 2). The increased discrepancies could be partially attributed to the errors introduced in mapping the random distribution of the aggregates and also the effect of aggregates on the porosity distribution of cement mortar, which is a challenging topic that is subject to further investigation.

Overall, it can be concluded that the proposed random porosity model with spatial correlation provides much improved predictions to the carbonation process of cement-based materials.

\section{Conclusions}

An improved multi-phase and -physics model for simulating supercritical carbonation process of cement-based materials has been presented in this paper. A random porosity model for cement-based materials has been used to simulate a supercritical carbonation test. The random field model of porosity based on the method of ellipsoidal autocorrelation function was developed to take into account the randomness and spatial correlation of porosity that follows a log normal distribution. Numerical results were obtained and compared with the experimental results. Parametric studies were carried out to assess the effect of average porosity and coefficient of variation on the carbonation profile and the carbonation depth. From the present study the following conclusions can be drawn:

1) The developed supercritical carbonation model with random porosity field can be used satisfactorily to simulate the carbonation process of cement-based materials with or without aggregates.

2) Introducing spatial correlation of porosity is essential in modelling carbonation of cement-based materials to simulate the non-uniform carbonation depth.

3) Though the simulated shapes of the non-carbonated zones are significantly different for different samples due to their randomly generated porosity distributions, the predicted average and maximum carbonation depths are more comparable across the samples. It was observed that the coefficient of variation of the predicted carbonation depths was always significantly smaller than 
that of porosity of the tested material.

4) Compared with the coefficient of variation, the average porosity has a more significant effect on the carbonation depth.

Though the random field model presented in this paper has produced reasonably satisfactory results in simulating carbonation of cement mortar and concrete, it was observed that the simulations for concrete were less comparable with the laboratory results. Further research is required to modify the random porosity model further so that the influence of aggregates on the random porosity distribution of concrete can be more accurately considered.

\section{References}

[1] Ashraf W. Carbonation of Cement-Based Materials: Challenges and Opportunities. Construction and Building Materials, 2016,120:558-570.

[2] Savija B, Lukovic M. Carbonation of Cement Paste: Understanding, Challenges, and Opportunities. Construction and Building Materials, 2016,117:285-301.

[3] Gonzalez J A, Algaba S, Andrade C. Corrosion of Reinforcing Bars in Carbonated Concrete. BRITISH CORROSION JOURNAL, 1980,15(3):135-139.

[4] Han J, Pan G, Sun W, et al. Application of Nanoindentation to Investigate Chemomechanical Properties Change of Cement Paste in the Carbonation Reaction. Science China-Technological Sciences, 2012,55(3):616-622.

[5] Fernández Bertos M, Simons S J R, Hills C D, et al. A Review of Accelerated Carbonation Technology in the Treatment of Cement-Based Materials and Sequestration of Co2. Journal of Hazardous Materials, 2004,112(3):193-205.

[6] Chi J M, Huang R, Yang C C. Effects of Carbonation On Mechanical Properties and Durability of Concrete Using Accelerated Testing Method. Journal of Marine Science and Technology, 2002,10(1):14-20.

[7] Garcia-Gonzalez C A, Hidalgo A, Andrade C, et al. Modification of Composition and Microstructure of Portland Cement Pastes as a Result of Natural and Supercritical Carbonation Procedures. Industrial \& Engineering Chemistry Research, 2006,45(14):4985-4992.

[8] Purnell P, Seneviratne A, Short N R, et al. Super-Critical Carbonation of Glass-Fibre Reinforced Cement. Part 2: Microstructural Observations. Composites Part a-Applied Science and Manufacturing, 2003,34(11):1105-1112.

[9] G Feng. Experimental and Numerical Study of Accelerated Carbonation in Cement BrickExperimental and Numerical Study of Accelerated Carbonation in Cement Brick and Tile. Harbin Institute of Technology,Master Degree in Engineering, 2013.(in Chinese)

[10] Zhan B, Poon C, Shi C. Co2 Curing for Improving the Properties of Concrete Blocks Containing Recycled Aggregates. Cement and Concrete Composites, 2013,42:1-8.

[11] Kou S, Zhan B, Poon C. Use of a Co2 Curing Step to Improve the Properties of Concrete Prepared with Recycled Aggregates. Cement and Concrete Composites, 2014,45:22-28.

[12] Shen J, Dangla P, Thiery M. Reactive Transport Modeling of Co2 through Cementitious Materials Under Co2 Geological Storage Conditions. International Journal of Greenhouse

*Correspondence author: Jianqiao Ye [j.ye2@lancaster.ac.uk] 
Gas Control, 2013,18:75-87.

[13] Zha X, Wang H, Xie P, et al. Leaching Resistance of Hazardous Waste Cement Solidification After Accelerated Carbonation. Cement \& Concrete Composites, 2016,72:125-132.

[14] Maekawa K, T I, T K. Multi-Scale Modeling of Structural Concrete.Taylor\&Francis, 2008.

[15] Zha X, Yu M, Ye J, et al. Numerical Modeling of Supercritical Carbonation Process in Cement-Based Materials. Cement and Concrete Research, 2015,72:10-20.

[16] Quoc T P, Maes N, Jacques D, et al. Modelling the Carbonation of Cement Pastes Under a Co2 Pressure Gradient Considering Both Diffusive and Convective Transport. Construction and Building Materials, 2016,114:333-351.

[17] Saetta A V, Schrefler B A, Vitaliani R V. The Carbonation of Concrete and the Mechanism of Moisture, Heat and Carbon-Dioxide Flow-through Porous Materials. Cement and Concrete Research, 1993,23(4):761-772.

[18] Rubin J B, Carey J W, Taylor C. Enhancement of Cemented Waste Forms by Supercritical Co2 Carbonation of Standard Portland Cements[M]//1997:473-478.

[19] Beasley K J. Carbon Dating Concrete Cracks. Journal of Performance of Constructed Facilities, 2015,29(025140021).

[20] Samouh H, Soive A, Roziere E, et al. Experimental and Numerical Study of Size Effect On Long-Term Drying Behavior of Concrete: Influence of Drying Depth. Materials and Structures, 2016,49(10):4029-4048.

[21] Chang C, Chen J. The Experimental Investigation of Concrete Carbonation Depth. Cement and Concrete Research, 2006,36(9):1760-1767.

[22] P Zichao, R Xin, C Airong. Numerical Simulation of Concrete Carbonation Process on Meso-scale. Journal of Tongji University(Natural Science), 2012,40(6):900-905.(in Chinese)

[23] Rimmele G, Barlet-Gouedard V, Porcherie O, et al. Heterogeneous Porosity Distribution in Portland Cement Exposed to $\mathrm{Co}(2)$-Rich Fluids. Cement and Concrete Research, 2008,38(8-9):1038-1048.

[24] L U Xiufeng, L Xila, Q Weizu. Moisture distribution of concrete in nature climate. SICHUAN BUILDING SCIENCE, 2007,33(5):114-117, 121.(in Chinese)

[25] Han J, Liu W, Wang S, et al. Effects of Crack and Itz and Aggregate On Carbonation Penetration Based On 3D Micro X-Ray Ct Microstructure Evolution. Construction and Building Materials, 2016,128:256-271.

[26] Huang Q, Jiang Z, Zhang W, et al. Numerical Analysis of the Effect of Coarse Aggregate Distribution On Concrete Carbonation. Construction and Building Materials, 2012,37:27-35.

[27] Ruan X, Pan Z. Mesoscopic Simulation Method of Concrete Carbonation Process. Structure and Infrastructure Engineering, 2012,8(2):99-110.

[28] Liang S, Ren X, Li J. A Random Medium Model for Simulation of Concrete Failure. Science China-Technological Sciences, 2013,56(5):1273-1281.

[29] Wriggers P, Moftah S O. Mesoscale Models for Concrete: Homogenisation and Damage Behaviour. Finite Elements in Analysis and Design, 2006,42(7):623-636.

[30] Liu Q, Li L, Easterbrook D, et al. Multi-Phase Modelling of Ionic Transport in Concrete When Subjected to an Externally Applied Electric Field. Engineering Structures, 2012,42:201-213.

[31] Diamond S D W L. Generalized Log-Normal Distribution of Pore Sizes in Hydrated Cement Paste. Journal of Colloid and Interface Science, 1972,38(1):234-244. 
[32] Shi D, Brown P W, Ma W. Lognormal Simulation of Pore Size Distributions in Cementitious Materials. Journal of the American Ceramic Society, 1991,74(8):1861-1867.

[33] Y Liu, B Huang, L Wang. Characteristics of injection pressure and saturation distributions of supercritical CO_2 injecting into heterogeneous saline aquifers. JOURNAL OF CHEMICAL INDUSTRY AND ENGINEERING(CHINA), 2010,61(1):32-42.(in Chinese)

[34] Li L. A Pore Size Distribution-Based Chloride Transport Model in Concrete. Magazine of Concrete Research, 2014,66(18):937-947.

[35] Lin L, Chen J, Zhang X, et al. A Novel 2-D Random Void Model and its Application in Ultrasonically Determined Void Content for Composite Materials. Ndt \& E International, 2011,44(3):254-260.

[36] Z Xiao-Ling, J Hao. Study on Pseudo-Random Number of Arbitrariness Probability Distributing and Its Implementation. Computer Technology and Development, 2007,17(12):116-118.(in Chinese)

[37] Ikelle L T, Yung S K, Daube F. 2-D Random-Media with Ellipsoidal Autocorrelation Functions. Geophysics, 1993,58(9):1359-1372.

[38] Y Zhao, L Lin, Z Ma, et al. Establishing TBC Random Pore Model Based on Random Media Theory. China Surface Enginerring, 2010,23(2):78-81.(in Chinese)

[39] Bary B, Sellier A. Coupled Moisture-Carbon Dioxide-Calcium Transfer Model for Carbonation of Concrete. Cement and Concrete Research, 2004,34(10):1859-1872.

[40] Baroghel-Bouny V, Thiéry M, Wang X. Modelling of Isothermal Coupled Moisture-Ion Transport in Cementitious Materials. Cement and Concrete Research, 2011,41(8):828-841.

[41] Mainguy M, Coussy O, Baroghel-Bouny V. Role of Air Pressure in Drying of Weakly Permeable Materials. JOURNAL OF ENGINEERING MECHANICS-ASCE, 2001,127(6):582-592.

[42] Comsol Multiphysics. Comsol Multiphysics User Guide (Version 4.3a).2012.

[43] Yaman I O, Hearn N, Aktan H M. Active and Non-Active Porosity in Concrete - Part I: Experimental Evidence. Materials and Structures, 2002,35(246):102-109. 